\title{
'Monrepos', a Plum Rootstock for Cherries
}

\author{
Ana Pina1, Pilar Errea, Ana Wünsch, and Rafael Gella \\ Fruit Tree Department, Agrifood Research and Technology Center of Aragon \\ (CITA), Avda Montañana, 930, 50059, Zaragoza, Spain
}

Additional index words. breeding, Prunus spp., propagation, compatibility

'Monrepos' is a Prunus-plum rootstock developed at the Agri-Food Research and Technology Center of Aragón (CITA), Zaragoza, Spain, for use as a rootstock for sweet cherry (Prunus avium L.). Cherry rootstock research over the last decade has been focused more on rootstock evaluation than on breeding new rootstocks (Hrotkó, 2008). Initially, dwarfing potential was the main focus for cherry rootstocks breeding programs. However, many challenges remain to be addressed in the areas of adaptation to biotic and abiotic stresses, graft compatibility, and rootstock influence on scion performance and fruit quality. In Spain and other Mediterranean countries, Prunus mahaleb L. (St Lucie) and its clone, SL 64, are widely used as cherry rootstocks in gravelly, well-drained, droughty, and calcareous soils. However, P. mahaleb L. rootstocks are unsuitable on heavy soils or where waterlogging occurs. In heavy soils or when replanting old orchard soils, $P$. cerasus (CAB series), MxM 14, and Adara (P. cerasifera L.) can reduce the problem of soil fungi in some circumstances (Perez, 2005), although some cherry cultivars are incompatible. New rootstocks suitable for use with sweet cherry are needed to solve the problems of soil adaptation, vigor, and graft incompatibility of the traditionally used rootstocks (Hormaza and Gella, 1996; Sansavini and Lugli, 2008).

'Monrepos' was selected from eight initial clones, because it shows good compatibility with a wide range of cherry cultivars, good adaptation to calcareous and heavy soils with high lime content, high productivity, and good rooting aptitude. In a flood-irrigated trial established in calcareous soil, $\mathrm{pH} 8.3$

Received for publication 22 July 2010. Accepted for publication 13 Dec. 2010.

This work was financed by the Instituto Nacional de Investigación y Tecnología Agraria y Alimentaria (INIA), grant no. RTA06-00087 and RTA09-00128, and by the Comisión Interministerial de Ciencia y Tecnología (CICYT), grant no. AGL-2001-2414C04-02.

We thank J. Rodrigo and M.J Rubio for critical reading of the manuscript. We grafetully acknowledge Rosa Fustero, Teresa Bespín, Pilar Tomey, Susana Ruber, and Jesús Castillo for technical assistance. We also thank the comments and suggestions of all anonymous reviewers, who critically contributed to improve the original version of this manuscript.

${ }^{1}$ To whom reprint requests should be addressed; e-mail apina@aragon.es. with active lime content and clay-loam texture, the clone was highly productive. Plants propagate well by in vitro and hardwood cuttings methods that makes it a valuable rootstock for small propagator companies or the largest producers of fruit rootstocks. 'Monrepos' offers a better production alternative for cherry cultivars, especially in heavy soils under flood irrigation conditions where other traditional cherry rootstocks fail to survive.

\section{Origin}

'Monrepos' is a rootstock selected from an open-pollinated population of Myrobolan (P. cerasifera Ehr.). Selection of this rootstock was carried out at CITA of Aragon, Spain. The genotype 'Monrepos' was analyzed and compared with the genotypes of two $P$. domestica L. ('Green Reine Claude' and 'Reine Claude Doree'), two $P$. insititia L. ('San Julian', and 'Adesoto 101'), two $P$. cerasifera Ehrh. ('Myrobolan B' and 'Myrobolan 29C'), and two P. persica L. Batsch. cultivars (Jesca and Evaisa) using 15 microsatellite (simple sequence repeats) markers previously selected for Prunus rootstock characterization by Serrano et al. (2002). The unweighted pair group method with arithmetic averages (UPGMA) grouping resulting from the similarity matrix from the microsatellite loci analyzed, grouped 'Monrepos' in the same cluster of the two $P$. cerasifera L. cultivars analyzed and separated from the rest of the genotypes, indicating that genotypically 'Monrepos' is more similar to P. cerasifera species (similarity 0.29 ).

\section{Description}

'Monrepos' unbudded trees are medium/ high vigorous with a very uniform and spreading growth and strong branching habit. Oneyear-old shoots are dark purple (RHS183A; The Royal Horticultural Society, 2005) and have medium thickness. Mature shoots are dark green (RHS 137A). The internodes are medium in length ranging from 12 to $17 \mathrm{~mm}$ without pubescences and a small number of lenticels. Shoot apex has strong anthocyanin coloration. In the 1-year-old shoots, the size of vegetative buds is small, acute-shaped, and the size of vegetative bud support is medium according to the UPOV's (2002) descriptors. By the end of summer, they show medium tendency to branch.
The young leaves have a strong anthocyanin coloration that later fade away during the growing season. The shape of the leaf blade is elliptic and medium size. Mean length is $7.1 \pm 0.95 \mathrm{~cm}$ and mean width $3.98 \pm 0.51$ $\mathrm{cm}$. Mean length/width ratio of the leaf blade is $1.791 \pm 0.72$, slightly lower than that of 'Myrobolan B' $(1.86 \pm 0.03)$ and higher than that of 'Adara' $(1.41 \pm 0.06)$ (Moreno et al., 1995). The length of the tip is medium and the leaf blade's base is obtuse. The upper side of leaf blade is dark (RHS 141A) and without pubescence on the lower side of the apex. The lower side surface is lighter green (RHS 137C). Leaf blades have shallow serrated margins. Leaf petioles are short-ranging with a mean length $15.53 \pm 2.48 \mathrm{~mm}$ and $\approx 1 \mathrm{~mm}$ thickness with a dark purple color (RHS 183A) and pubescence is lacking along the top of the petiole. No stipules are developed at the base of the leaves.

Flower budbreak on 'Monrepos' occurs at the same time as 'Myrobolan B' and earlier than 'Colt', 'SL-64', 'F-12/1', and 'St. Julian A'. The flowers are white and slightly larger than those of 'Myrobolan B'. The fruits are round, thick with a gold yellow skin. Fruit mean weight is $9.3 \mathrm{~g} \pm 0.75$ with a diameter of $25.07 \pm 0.9$ and a height of $25.15 \pm 0.67$ (length/height $=1 \pm 0.02$ ). Fruits typically ripen in the third week of July after other Myrobolan of yellow fruit. The peduncule length is short with a mean length of $15.5 \pm$ $0.7 \mathrm{~mm}$, thin, and with a shallow peduncular cavity. The fruit flesh is yellow (RHS 15D), bittersweet, and it has an adherent stone of medium size.

\section{Performance}

Over the past 7 years, this rootstock has been propagated by hardwood cuttings treated with indole-3-butyric acid at $2000 \mathrm{ppm}$ for $10 \mathrm{~s}$ and then directly planted into nursery rows in late fall. A rooting ratio higher than $90 \%$ was obtained all years, presenting good aptitude for propagation. 'Monrepos' can also be propagated by in vitro techniques with a high proportion of rooting values similar to 'Myrobolan 29C'. The root induction is $87.2 \% \pm 9.2 \%$ and four or five roots per shoot observed ranging from 2 to $4 \mathrm{~cm}$ in length. The in vitro-grown plantlets were successfully established in the greenhouse with $96 \%$ survival.

The eight initial clones selected were evaluated with at least 50 cherry cultivars of commercial value in the Ebro's Valley region. Some cultivars showed symptoms of delayed incompatibility with some of the rootstock clones, but 'Monrepos' was selected for its better compatibility without showing visual symptoms. To study the behavior of the selected 'Monrepos' rootstock, it was grafted with eight cultivars and examined microscopically 1 year later. The cross-section of the graftings studied presented a high degree of differentiation and a great number of sieve plates indicating good symplasmic continuity, a prerequisite for effective translocation between both graft partners (Schöning and 
Table 1. Trunk cross-sectional area (TCSA), yield, yield efficiency, and soluble solid content (SSC) of 'Compact Stella' grafted on different rootstocks in a 7-year-flood-irrigated trial established in Zaragoza, Spain, on highly calcareous soil, pH 8.3 with active (9\% to $10 \%)$ lime content and clay-loam.

\begin{tabular}{lcccc}
\hline Rootstock & TCSA $\left(\mathrm{cm}^{2}\right)$ & $\begin{array}{c}\text { Yield } \\
(\mathrm{kg} / \text { tree })\end{array}$ & $\begin{array}{c}\text { Yield efficiency } \\
\left(\mathrm{kg} \cdot \mathrm{cm}^{-2}\right)\end{array}$ & SSC $\left({ }^{\circ} \mathrm{Brix}\right)$ \\
\hline Gisela 5 & $44.59 \mathrm{c}^{\mathrm{z}}$ & $6.46 \mathrm{cb}$ & $0.14 \mathrm{a}$ & $16.02 \mathrm{a}$ \\
Masto Montañana & $116.58 \mathrm{~b}$ & $3.01 \mathrm{~d}$ & $0.03 \mathrm{c}$ & $17.10 \mathrm{a}$ \\
Monrepos & $173.69 \mathrm{a}$ & $11.85 \mathrm{a}$ & $0.07 \mathrm{~b}$ & $16.33 \mathrm{a}$ \\
CAB 6-P & $102.70 \mathrm{~b}$ & $3.82 \mathrm{dc}$ & $0.04 \mathrm{c}$ & $16.10 \mathrm{a}$ \\
SL-64 & $120.73 \mathrm{~b}$ & $7.89 \mathrm{~b}$ & $0.08 \mathrm{~b}$ & $16.59 \mathrm{a}$ \\
\hline
\end{tabular}

${ }^{\mathrm{z}}$ Means within a column followed by the same letter are not significantly different, mean separation within column by least significant difference test at $P \leq 0.05$.

Kollmann, 1997). In addition to these observations, in the years 2000 and 2001, the selected clone 'Monrepos' was grafted with 29 sweet and sour cherry cultivars commercially available in this region: 'Blackgold', 'Brooks', 'Burlat', 'Celeste', 'Compact Stella', 'Cristalina', 'Earlise', 'Early Bigi', 'Lapins', '13S-03-13', 'Margit', 'Newstar', 'NY 7679', 'NY 7690', 'Panaro 1', 'Prime Giant', 'Primulat', 'Regina', 'Samba', 'Santina', 'Skeena', 'Sommerset', 'Sonata', 'Stark Hardy Giant', 'Sumesi', 'Summit', 'Sunburst', 'Sweethearth', and 'Sylvia'. Twelve trees were studied from each cultivar. During 5 years, the graft combinations were tested macroscopically in nursery trials observing the longitudinal section and rating the symptoms according to the criteria of Herrero (1951). All combinations were found to be compatible showing continuous bark and wood in the union.

During the 7 years of field trials, in a flood-irrigated trial established in Zaragoza, Spain, on highly calcareous soil, $\mathrm{pH} 8.3$ with active $(9 \%$ to $10 \%)$ lime content and clayloam texture, 'Monrepos' was compared with the cherry rootstocks 'Gisela 5' ( $P$. cerasus $\times$ $P$. canescens), 'Santa Lucia 64' ( $P$. mahaleb), 'CAB6P' (P. cerasus), and 'Masto de Montañana' ( $P$. cerasus). These rootstocks range from low to high vigor, with 'Gisela 5' classed as a dwarfing rootstock, 'Masto de Montañana' and 'CAB6P' as intermediate vigor rootstocks, and 'St Lucia 64' as a medium/high vigor rootstock. The SPAD values
Zaragoza, Spain. The original 'Monrepos' clone has been serologically tested and it is free from the viruses prune dwarf virus, prunus necrotic ringspot virus, apple chlorotic leaf spot virus, plum pox virus, and apple mosaic virus. It has also been tested with GF 305 and $P$. serrulata cv. Shirofugen indicators. In all cases, the results showed absence of symptoms of diseases caused by viruses or phytoplasmas.

\section{Literature Cited}

taken in 2010 showed higher chlorophyll content in 'Monrepos' 39.675 than in the rootstock 'Gisela 5' 38.925. The fruit size induced to the cherry cultivar Compact Stella was similar on 'Monrepos' and 'SL 64' (between 22 and $24 \mathrm{~mm}$ in width) and greater than on 'Gisela 5' (17 to $20 \mathrm{~mm}$ in width). The poor tree growth induced by 'Gisela 5 ' in the Mediterranean area was also reported by Jiménez et al. (2007).

Tree growth showed the higher values on 'Monrepos' and lower values on 'Gisela 5' throughout the years of evaluation (Table 1). By seventh year after grafting, the yield for 'Compact Stella' was greater on 'Monrepos' rootstock, whereas the highest yield efficiency was recorded in 'Gisela 5' and the lowest on 'CAB6P' and 'Masto de Montañana' (Table 1). Differences in soluble solid content were not detected among the different rootstocks. This plum rootstock has provided a vigor and yield efficiency close to 'SL 64 ' as well as a good adaptation to irrigated conditions. Only 'Gisela 5' showed greater yield efficiency than 'Monrepos' in our Mediterranean climatic conditions as a result of the lowest vigor of the first rootstock.

\section{Availability}

'Monrepos' registration is in process. Small amounts of rooted cuttings or budwood can be obtained from the Agri-Food Research and Technology Center of Aragon (CITA),
Herrero, 1951. Studies of compatible and incompatible graft combinations with special reference to hardy fruit trees. J. Hort. Sci. 26:186-237.

Hormaza, J.I. and R. Gella. 1996. Situación actual de los patrones de cerezo. Fruticultura Profesional 80:5-15.

Hrotkó, K. 2008. Progress in cherry rootstock research. Acta Hort. 795:171-178.

Jiménez, S., J. Pinochet, Y. Gogorcena, J.A. Betran, and M.A. Moreno. 2007. Influence of different vigour cherry rootstocks on leaves and shoots mineral composition. Sci. Hort. 112:73-79.

Moreno, M.A., M.C. Tabuenca, and R. Cambra. 1995. Adara, a plum rootstock for cherries and other stone fruit species. HortScience 30:13161317.

Perez, J.N. 2005. Cherry cultivation in Spain. 4th International Cherry Symposium. Proc. of the IVth International Cherry Symposium, Vols 1 and 2. 667:293-301.

Sansavini, S. and S. Lugli. 2008. Sweet breeding programs in Europe and Asia. Acta Hort. 795: $41-58$.

Schöning, U. and R. Kollmann. 1997. Phloem translocation in regenerating in vitro-heterografts of different compatibility. J. Expt. Bot. 48:289-295.

Serrano, B., J. Gómez-Aparisi, and J.I. Hormaza 2002. Molecular fingerprinting of Prunus rootstocks using SSRs. J. Hort. Sci. Biotechnol. 77: 368-372.

The Royal Horticultural Society (RHS). 2005. Minicolour chart. London, UK.

UPOV. 2002. International Union for the Protection of New Varieties of Plants. Guidelines for the conduct of tests for distinctness, uniformity and stability. Prunus rootstocks (Prunus L). Document TG/187/1, UPOV, Geneva, Switzerland. 